\title{
Research Paper: The Relationship Between Vitamin D Levels and the Severity of Anxiety and Depression in Patients Under Methadone Maintenance Treatment
}

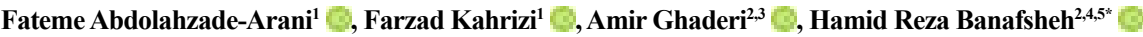 \\ 1. Department of Pharmacology and Toxicology, Faculty of Pharmacy, Damghan Branch, Islamic Azad University, Damghan, Iran. \\ 2. Department of Addiction Studies, School of Medicine, Kashan University of Medical Sciences, Kashan, Iran. \\ 3. Clinical Research Development Unit-Matini/Kargarnejad Hospital, Kashan University of Medical Sciences, Kashan, Iran. \\ 4. Research Center for Physiology Science, Kashan University of Medical Sciences, Kashan, Iran. \\ 5. Department of Pharmacology, Faculty of Medicine, Kashan University of Medical Sciences, Kashan, Iran.
}

$\begin{aligned} & \text { Use your device to scan } \\ & \text { and read the article online }\end{aligned}$
Severity of Anxiety and Depression in Patients Under Methadone Maintenance Treatment. International Journal of Medical
Toxicology and Forensic Medicine. 2021; 11(3):34968. https://doi.org/10.32598/ijmtfm.v11i3.34968
d. https://doi.org/10.32598/ijmtfm.v11i3.34968

Article info:

Received: 23 May 2021

First Revision: 5 Jun 2021

Accepted: 22 Jun 2021

Published: 25 Aug 2021

\section{Keywords:}

Vitamin D, Anxiety, Depression, Methadone

\section{ABSTRACT}

Background: Hypovitaminosis D, low bone mineral density, non-specific musculoskeletal pain, increased risk of fracture, and periodontal disease were reported in most subjects recruited from the Methadone Maintenance Treatment (MMT) program. This study aimed to determine the relationship between vitamin $\mathrm{D}$ levels and the severity of anxiety and depression in patients under MMT.

Methods: In a cross-sectional study, serum vitamin D levels were measured among 500 patients under MMT from Kashan Province, Iran. Correlation tests were used to assess the association of vitamin D levels with the severity of anxiety and depression in the explored patients.

Results: We found that serum vitamin D levels were positively correlated with the scores of the Beck Depression Inventory (BDI) $(r=0.107, \mathrm{P}=0.017)$ and the Beck Anxiety Inventory (BAI) $(\mathrm{r}=0.129, \mathrm{P}=0.004)$. Additionally, there was a negative correlation between serum vitamin $\mathrm{D}$ levels, MMT dosage $(\mathrm{r}=-0.011, \mathrm{P}=0.8)$, and the duration of MMT $(\mathrm{r}=-0.017, \mathrm{P}=0.7)$.

Conclusion: Our findings demonstrated that serum vitamin D levels were independently correlated with the BDI and BAI scores. Further studies are required to confirm our findings.

\footnotetext{
* Corresponding Author:

Hamid Reza Banafshe, PhD.

Address: Research Center for Physiology Science, Kashan University of Medical Sciences, Kashan, Iran. Tel: +98 (31) 55463378?

E-mail: banafshe57@hotmail.com
} 


\section{Introduction}

llicit drug use is a significant public and social health challenge and a major risk I factor for other health problems in Iran [1]. In 2018, opioid use was prevalent globally, with the past year prevalence of $1.2 \%$ in the population aged $15-64$ years, i.e., a $0.7 \%$ increase. The prevalence of 12-month use of any illicit drug according to the Diagnostic and Statistical Manual of Mental Disorders, Fourth Edition (DSM-IV) and the Diagnostic and Statistical Manual of Mental Disorders, Fifth Edition (DSM-5) criteria were reported to be $2.1 \%$ and $2.4 \%$, respectively. Based on the epidemiology of illicit drug use disorders in Iran, opioid use disorders were the most common form of illicit drug use. Furthermore, the types of opioids used by individuals with a diagnosis of opioid use disorder were opium (82.3\%), opium shireh (27.8\%), methadone (non-medical) $(16.6 \%)$, the heroin/crack of heroin $(16.1 \%)$, and morphine (2.6\%). The frequencies add up to $\geq 100 \%$. This is because some subjects used more than one type of opioid [2-4].

Methadone Maintenance Therapy (MMT) is suggested for treating opioid use disorders [4]. However, the main focus has been placed on the treatment of opioid dependence in Iran. There exists around 5000 buprenorphine or MMT clinics; thus, approximately 500000 subjects are under treatment $[5,6]$. However, despite the extensive and successful implementation of MMT, numerous challenges and obstacles remain unaddressed. The psychiatric effects of MMT include such problems, as cognitive impairment, depression, and anxiety symptoms, as well as sleep disturbances [7].

Among all micronutrients, 25 (O.H.) vitamin D deficiency is currently considered a significant health problem. According to the world estimations, more than one billion individuals experience low vitamin D levels [8,9]. Tabrizi et al. indicated that the prevalence of vitamin D deficiency among male, female, and pregnant women was estimated to be $45.64 \%, 61.90 \%$, and $60.45 \%$ in the Iranian population, respectively [10]. Vitamin D plays an essential role in the human population's survival, public health, and fertility [11]. Evidence emphasized its role in preventing diseases, such as multiple sclerosis, type 1 diabetes mellitus, heart diseases, rheumatoid arthritis, malignancies, infectious diseases, and immune disorders $[12,13]$. Moreover, hypovitaminosis D, low Bone Mineral Density (BMD), non-specific musculoskeletal pain, increased risk of fracture, and periodontal disease were reported in most subjects recruited from the MMT program [14].
International data representing the circulating vitamin D status in patients with MMT are scarce. Kim et al. [15] reported low vitamin D status among 52\%, vitamin $\mathrm{D}$ deficiency in $36 \%$, and insufficiency in an additional $16 \%$ in the Boston public health commission's MMT program. They also highlighted that this finding was nonspecific to MMT but common among debilitated populations. Furthermore, recent evidence demonstrated that the mean vitamin status was $<14 \mathrm{ng} / \mathrm{mL}$ in 60 patients under MMT; most patients presented vitamin D deficiency [16]. Besides, several human studies have indicated that low circulating vitamin D status was associated with depressive and anxiety symptoms [17-19]; however, some investigations detected no significant relationship in this regard [20, 21]. Vitamin D is involved in brain development and multiple central nervous system processes, including neuromodulation and neuroprotection; thus, this molecule may affect psychological illnesses [22].

To our knowledge, no study evaluated the association between vitamin $\mathrm{D}$ levels and the severity of mental health disorders in patients under MMT. A better understanding of the contribution of vitamin D to the mental health of MMT subjects could lead to pragmatic interventions to identify patients under drug abuse treatment who are at risk for vitamin D deficiency. Therefore, the present study aimed to investigate the widespread low vitamin $\mathrm{D}$ status and its association with depression and anxiety in patients receiving MMT.

\section{Materials and Methods}

This cross-sectional study was conducted among 500 participants under MMT in Kashan Province, Iran, including Soltan Mirahmad Clinic. The Ethics Committee of Damghan Branch, Islamic Azad University, approved this study (code: IR.IAU.DAMGHAN.REC.1400.010). This investigation was conducted per the Declaration of Helsinki, and a written informed consent form was obtained from all research subjects. All informed consent forms were reviewed by the Institutional Ethics Committee of Islamic Azad University Damghan. The inclusion criteria of the study included the age of $18-75$ years and receiving MMT in the past 3 months, as assessed by the substance abuse section of the Structured Clinical Interview for the DSM-IV criteria. The exclusion criteria were as follows: presenting psychotic symptoms in the past 6 months, having metabolic diseases, such as diabetes and neurological disorders, the presence of kidney, liver, hematologic, and thyroid diseases, the Human Immunodeficiency Viruses (HIV), and any other chronic physical illness, positive urine test for methamphetamine 
and cannabis, as well as unwillingness to cooperate in the research project.

The demographic measures of the study participants were established using a standard scale (Seca, Hamburg, Germany) at the baseline (e.g., age, gender, weight, height, educational level, material status, occupational status, MMT duration, methadone dose, \& cigarette smoking). Body Mass Index (BMI) was also calculated for the study subjects.

The Beck Depression Inventory (BDI) was used to assess depression. The Beck Anxiety Inventory (BAI), developed by Beck et al., was employed to determine the frequency of anxiety signs in the explored adults.

At baseline, $5 \mathrm{~mL}$ of fasting blood samples were collected from each explored patient at Kashan reference laboratory. Serum 25-hydroxyvitamin D values were measured using the Enzyme-Linked Immunosorbent Assay (ELISA) kit (IDS, Boldon, UK) with intra- and inter-assay Coefficient Variances (CVs) below 7\%.

We used a correlation test to assess the association between vitamin D levels and the severity of the BDI and BAI scores, MMT dosage, and the duration of MMT in patients under MMT. $\mathrm{P}<0.05$ was considered significant. SPSS was used for data analysis.

\section{Results}

Totally, 500 patients with MMT, aged 24-71 years participated in the current study. Of them, 458(91.6\%) subjects were male. The mean age of the explored patients was 41.3 years. Besides, the mean age of the first consumption of illicit substances was 19.6 years (Table 1). Among the studied cases, 457(91.4\%), 36(7.2\%), and 7(1.4\%) of the patients presented a deficiency, insufficiency, and normal levels of vitamin D, respectively (Table 1).

We found that serum vitamin D levels were positively correlated with the scores of BDI $(r=0.107, \mathrm{P}=0.017)$ and BAI $(r=0.129, \mathrm{P}=0.004)$. Moreover, there were negative correlations between serum vitamin $\mathrm{D}$ levels and MMT dose $(\mathrm{r}=-0.011, \mathrm{P}=0.8)$, and the duration of MMT $(\mathrm{r}=-0.017, \mathrm{P}=0.7)$ (Table 2).

\section{Discussion}

The present study findings displayed a significant positive association between serum vitamin D levels and anxiety and depression in patients under MMT. Vitamin $\mathrm{D}$ is a lipid-soluble secosteroid, i.e., some hormonal ac- tions [23]. Vitamin D can regulate several neurotransmission pathways at the central and regional levels, including norepinephrine, dopamine, serotonin, and glutamine [24]. Furthermore, vitamin D receptor is extensively expressed in the hypothalamus, substantia nigra, and human brain tissue, indicating mental health disorders may be associated with vitamin D deficiency [25].

Previous studies have investigated the association between vitamin $\mathrm{D}$ concentrations and mental health status in various conditions. In a study by Zhou et al., 25-hydroxyvitamin D3 levels were inversely correlated with depression severity in subjects with gout [26]. Additionally, the negative associations of cholecalciferol levels with the severity of depression were significant among subjects with ischemic stroke [27]. Fond et al. also indicated that lower vitamin D3 values were associated with higher depressive symptoms, independently of gender and age, among patients with schizophrenia [28]. Another study reported a negative relationship between vitamin D3 levels and depressive symptoms in Chinese longevous individuals [29].

Moreover, Han et al. demonstrated that low levels of vitamin D3 were correlated with anxiety in children under dialysis [30]. In a meta-analysis of observational studies, $\mathrm{Ju}$ et al. documented an inverse correlation between the risk of depression and vitamin D concentrations [31]. Administrating 50000 IU vitamin D3 biweekly to individuals under MMT significantly attenuated the severity of anxiety and depression after 12 weeks [16]. However, as per Casseb et al., vitamin D3 levels were not significantly associated with anxiety and depression scores in healthy subjects [32]. Furthermore, there was no correlation between vitamin $\mathrm{D}$ levels and the severity of mental health disorders in individuals with fibromyalgia [33]. Furthermore, there was no relationship between vitamin D concentrations and the severity of depression among young women [34]. Divergence among the results of various studies may be due to differences in the specific features of participants, geographic area, ethnicity, age, and comorbidity. Extensive evidence has demonstrated that vitamin D may affect behavior and mood disorders. This process is effected by regulating the synthesis of neurotrophic factors and neurotransmitters involved in the physiopathology of mental health illnesses [35].

Vitamin D may play a crucial role in attenuating mental problems via enhancing tyrosine hydroxylase expression and increasing the bioavailability of multiple neurotransmitters, such as norepinephrine and dopamine [36]. The other major mechanisms by which vitamin D may influence mental health status include dopamine receptor 
Table 1. The demographic characteristics and the parameters of mental health in the study participants

\begin{tabular}{|c|c|c|}
\hline \multicolumn{2}{|c|}{ Variables } & Mean $\pm S D /$ No. (\%) \\
\hline \multicolumn{2}{|c|}{ Age (y) } & $41.3 \pm 9.9$ \\
\hline \multicolumn{2}{|c|}{ Age of first illicit substance use (y) } & $19.6 \pm 3.5$ \\
\hline \multirow{3}{*}{ Gender } & Female & $42(8.4)$ \\
\hline & & \\
\hline & Male & $458(91.6)$ \\
\hline \multicolumn{2}{|c|}{ Height (m) } & $170.8 \pm 8.1$ \\
\hline \multicolumn{2}{|c|}{ Wight (kg) } & $70.7 \pm 10.5$ \\
\hline \multicolumn{2}{|c|}{ Body Mass Index $\left(\mathrm{kg} / \mathrm{m}^{2}\right)$} & $24.2 \pm 3.3$ \\
\hline \multicolumn{2}{|c|}{ BDI score } & $20.5 \pm 6.6$ \\
\hline \multicolumn{2}{|c|}{ BAl score } & $18.3 \pm 6.3$ \\
\hline \multicolumn{2}{|c|}{ Methadone dose $(\mathrm{mL} / \mathrm{d})$} & $18.0 \pm 5.8$ \\
\hline \multicolumn{2}{|c|}{ Duration of MMT (y) } & $6.6 \pm 2.9$ \\
\hline \multicolumn{2}{|c|}{ Vitamin D (ng/mL) } & $13.7 \pm 5.2$ \\
\hline \multirow{3}{*}{ Vitamin D levels } & Normal vitamin $\mathrm{D}(\geq 30 \mathrm{ng} / \mathrm{mL})$ & $7(1.4)$ \\
\hline & Insufficiency (20-29.9 ng/mL) & $36(7.2)$ \\
\hline & Deficiency $(<20 \mathrm{ng} / \mathrm{mL})$ & 457 (91.4) \\
\hline \multirow{5}{*}{ Education } & Illiterate & $102(20.4)$ \\
\hline & Elementary & $304(60.8)$ \\
\hline & Intermediate & $66(13.2)$ \\
\hline & Diploma & $20(4.0)$ \\
\hline & High educated & $8(1.6)$ \\
\hline \multirow{3}{*}{ Marital status } & Single & $166(33.2)$ \\
\hline & Married & $172(34.4)$ \\
\hline & Widow/Divorced & $162(32.4)$ \\
\hline \multirow{3}{*}{ Job } & Unemployed & $360(72.0)$ \\
\hline & Employed & $10(2.0)$ \\
\hline & Others & $130(26.0)$ \\
\hline \multirow{4}{*}{ History of Illicit Drugs Depe } & Opium and opium residues & $180(36.0)$ \\
\hline & Heroin (Crystal) & 96 (19.2) \\
\hline & Stimulants & $20(4.0)$ \\
\hline & Poly-drug users & $204(40.8)$ \\
\hline
\end{tabular}

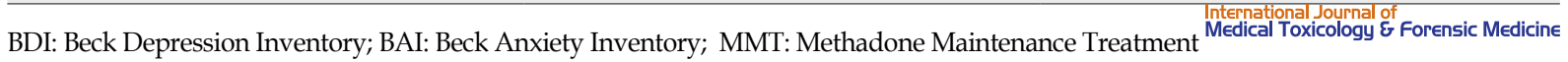


Table 2. Correlation test data concerning the parameters of mental health and vitamin D levels

\begin{tabular}{ccc}
\hline \multirow{2}{*}{ Parameters of Mental Health } & \multicolumn{2}{c}{ Vitamin D Levels } \\
\cline { 2 - 3 } & Pearson Correlation Coefficient & P \\
\hline BDI score & 0.107 & 0.017 \\
BAI score & 0.129 & 0.004 \\
MMT dosage & -0.011 & 0.800 \\
The duration of MMT & -0.017 & 0.701 \\
\hline BDI: Beck Depression Inventory; BAI: Beck Anxiety Inventory & International Journal of \\
Medical Toxicology \& Forensic Medicine
\end{tabular}

blockage [37], the augmentation of central serotonin production [38], the modulation of oxidative damage and inflammation [39-41], and the alteration of brain acetylcholinesterase activity [42].

In our research, lower vitamin D3 concentrations were associated with higher methadone dose and the duration of methadone therapy in patients under MMT. Hypovitaminosis D in individuals under MMT has been considered due to the high prevalence of chronic pain in substance-dependent populations [43, 44]. Patients under MMT program suffer from musculoskeletal discomforts associated with the adverse effects of methadone [45].

Low vitamin D status results in osteoporosis and diffuse chronic joint or limb pains [46]. In a study by Plotnikoff et al. [47], 93\% of the subjects with chronic pain presented vitamin D deficiency. Moreover, methadone (or all opioids) may decrease vitamin D concentrations by activating steroid and xenobiotic receptors [15]. Additionally, vitamin D deficiency is correlated with muscle weakness, lower respiratory functions [48], higher risk of falling [49], metabolic syndrome [50], and cardiovascular diseases [51]; such conditions can affect the quality of life in patients under MMT program.

There were some limitations in our research. A causal relationship between vitamin $\mathrm{D}$ and mental health disorders in patients under MMT could not be evaluated due to the study's cross-sectional design. Additionally, we did not use a structured diagnostic interview to evaluate psychological disorders, and only self-rating questionnaires were applied to determine the severity of anxiety and depression. Another important limitation was the lack of information, such as indoor and outdoor physical activity and dietary patterns, affecting vitamin $\mathrm{D}$ values and possibly anxiety and depressive symptoms in patients under MMT.

\section{Conclusion}

Our research data revealed that serum vitamin D levels are inversely associated with the severity of anxiety and depression in patients under MMT. Randomized clinical trials with a strong design, a larger sample size, and a proper dose of cholecalciferol are necessary for examining whether vitamin D administration is useful in treating depression and anxiety among patients under MMT.

\section{Ethical Considerations}

\section{Compliance with ethical guidelines}

All ethical principles are considered in this article. The Ethics Committee of Damghan Branch, Islamic Azad University approved this study (Code: IR.IAU. DAMGHAN.REC.1400.010).

\section{Funding}

The study was supported by a grant from Islamic Azad University Damghan Branch (Fatemeh Abdolahzade-Arani).

\section{Author's contributions}

Conceptualization and supervision: Amir Ghaderi and Hamid Reza Banafsheh; Writing original draft and Data analysis: Amir Ghaderi, Hamid Reza Banafsheh; Investigation: Fateme Abdolahzadeh-Arani and Farzad kahrizi; Final approval: All authors.

\section{Conflict of interest}

The authors declared no conflict of interest.

\section{Acknowledgements}

The authors would like to thank the substance abuse treatment center's staff for their contribution to this project. 


\section{References}

[1] Forouzanfar MH, Sepanlou SG, Shahraz S, Dicker D, Naghavi P, Pourmalek F, et al. Evaluating causes of death and morbidity in Iran, global burden of diseases, injuries, and risk factors study 2010. Arch Iran Med. 2014; 17(5):304-20. [PMID]

[2] United Nations Office on Drugs Crime. World drug report. New York: United Nations Publications; 2016. https:// books.google.com/books/about/World_Drug_Report_2016. html?id=zyWWDwAAQBAJ\&source=kp_book_description

[3] Amin-Esmaeili M, Rahimi-Movaghar A, Sharifi V, Hajebi A, Radgoodarzi R, Mojtabai R, et al. Epidemiology of illicit drug use disorders in Iran: Prevalence, correlates, comorbidity and service utilization results from the Iranian Mental Health Survey. Addiction (Abingdon, England). 2016; 111(10):1836-47. [DOI:10.1111/add.13453] [PMID]

[4] Kourounis G, Richards BD, Kyprianou E, Symeonidou E, Malliori MM, Samartzis L. Opioid substitution therapy: Lowering the treatment thresholds. Drug Alcohol Depend. 2016; 161:1-8. [DOI:10.1016/j.drugalcdep.2015.12.021] [PMID]

[5] Lankarani KB, Afshari R. Alcohol consumption in Iran. Lancet. 2014; 384(9958):1927-8. [DOI:10.1016/S0140-6736(14)62279-0]

[6] Lankarani KB, Alavian SM, Peymani P. Health in the Islamic republic of Iran, challenges and progresses. Med J Islam Repub Iran. 2013; 27(1):42-9. [PMCID]

[7] Callaly T, Trauer T, Munro L, Whelan G. Prevalence of psychiatric disorder in a methadone maintenance population. Aust N Z J Psychiatry. 2001; 35(5):601-5. [DOI:10.1080/0004867010060507] [PMID]

[8] Heaney RP, Dowell MS, Hale CA, Bendich A. Calcium absorption varies within the reference range for serum 25-hydroxyvitamin D. J Am Coll Nutr. 2003; 22(2):142-6. [DOI:10.10 80/07315724.2003.10719287] [PMID]

[9] Holick MF, Chen TC. Vitamin D deficiency: A worldwide problem with health consequences. Am J Clin Nutr. 2008; 87(4):1080s-6. [DOI:10.1093/ajcn/87.4.1080S] [PMID]

[10] Tabrizi R, Moosazadeh M, Akbari M, Dabbaghmanesh MH, Mohamadkhani M, Asemi Z, et al. High prevalence of vitamin d deficiency among Iranian population: A systematic review and meta-analysis. Iran J Med Sci. 2018; 43(2):125-39. [PMCID]

[11] Hagenau T, Vest R, Gissel TN, Poulsen CS, Erlandsen $\mathrm{M}$, Mosekilde L, et al. Global vitamin D levels in relation to age, gender, skin pigmentation and latitude: An ecologic meta-regression analysis. Osteoporos Int. 2009; 20(1):133-40. [DOI:10.1007/s00198-008-0626-y] [PMID]

[12] Holick MF. Sunlight and vitamin D for bone health and prevention of autoimmune diseases, cancers, and cardiovascular disease. Am J Clin Nutr. 2004; 80(6 S):1678s-88. [DOI:10.1093/ ajcn/80.6.1678S] [PMID]

[13] Holick MF. Vitamin D: Importance in the prevention of cancers, type 1 diabetes, heart disease, and osteoporosis. Am J Clin Nutr. 2004; 79(3):362-71. [DOI:10.1093/ajcn/79.3.362] [PMID]

[14] Kim TW, Alford DP, Malabanan A, Holick MF, Samet JH. Low bone density in patients receiving methadone maintenance treatment. Drug Alcohol Depend. 2006; 85(3):258-62. [DOI:10.1016/j.drugalcdep.2006.05.027] [PMID] [PMCID]
[15] Kim TW, Alford DP, Holick MF, Malabanan AO, Samet JH Low vitamin d status of patients in methadone maintenance treatment. J Addict Med. 2009; 3(3):134-8. [DOI:10.1097/ ADM.0b013e31819b736d] [PMID] [PMCID]

[16] Ghaderi A, Banafshe HR, Motmaen M, Rasouli-Azad M, Bahmani F, Asemi Z. Clinical trial of the effects of vitamin D supplementation on psychological symptoms and metabolic profiles in maintenance methadone treatment patients. Prog Neuropsychopharmacol Biol Psychiatry. 2017; 79(Pt B):84-9. [DOI:10.1016/j.pnpbp.2017.06.016] [PMID]

[17] Hoogendijk WJ, Lips P, Dik MG, Deeg DJ, Beekman AT, Penninx BW. Depression is associated with decreased 25-hydroxyvitamin D and increased parathyroid hormone levels in older adults. Arch Gen Psychiatry. 2008; 65(5):508-12 [DOI:10.1001/archpsyc.65.5.508] [PMID]

[18] LeeDM, Tajar A, O'Neill TW, O' ConnorDB, BartfaiG, Boonen $\mathrm{S}$, et al. Lower vitamin D levels are associated with depression among community-dwelling European men. J Psychopharmacol. 2011; 25(10):1320-8. [DOI:10.1177/0269881110379287] [PMID]

[19] Bicikova M, Duskova M, Vitku J, Kalvachova B, Ripova D, Mohr $\mathrm{P}$, et al. Vitamin D in anxiety and affective disorders. Physiol Res 2015; 64(S2):S101-3. [DOI:10.33549/physiolres.933082] [PMID]

[20] Zhao G, Ford ES, Li C, Balluz LS. No associations between serum concentrations of 25-hydroxyvitamin $D$ and parathyroid hormone and depression among U.S. adults. Br J Nutr. 2010; 104(11):1696-702. [DOI:10.1017/S0007114510002588] [PMID]

[21] Can MS, Baykan H, Baykan O, Erensoy N, Karlidere T. Vitamin D levels and vitamin D receptor gene polymorphism in major depression. Psychiatr Danub. 2017; 29(2):179-85. [DOI:10.24869/psyd.2017.179] [PMID]

[22] Fernandes de Abreu DA, Eyles D, Feron F. Vitamin D, a neuro-immunomodulator: Implications for neurodegenerative and autoimmune diseases. Psychoneuroendocrinology. 2009; 34(S1):S265-77. [DOI:10.1016/j.psyneuen.2009.05.023] [PMID]

[23] Sassi F, Tamone C, D’Amelio P. Vitamin D: Nutrient, hormone, and immunomodulator. Nutrients. 2018; 10(11):1656 [DOI:10.3390/nu10111656] [PMID] [PMCID]

[24] Kesby JP, Turner KM, Alexander S, Eyles DW, McGrath JJ, Burne THJ. Developmental vitamin D deficiency alters multiple neurotransmitter systems in the neonatal rat brain. Int J Dev Neurosci. 2017; 62:1-7. [DOI:10.1016/j. ijdevneu.2017.07.002] [PMID]

[25] Eyles DW, Smith S, Kinobe R, Hewison M, McGrath JJ. Distribution of the vitamin D receptor and 1 alpha-hydroxylase in human brain. J Chem Neuroanat. 2005; 29(1):21-30. [DOI:10.1016/j.jchemneu.2004.08.006] [PMID]

[26] Zhou Q, Shao YC, Gan ZQ, Fang LS. Lower vitamin D levels are associated with depression in patients with gout. Neuropsychiatr Dis Treat. 2019; 15:227-31. [DOI:10.2147/NDT. S193114] [PMID] [PMCID]

[27] Kim SH, Seok H, Kim DS. Relationship between serum vitamin $\mathrm{D}$ levels and symptoms of depression in stroke patients. Ann Rehabil Med. 2016; 40(1):120-5. [DOI:10.5535/ arm.2016.40.1.120] [PMID] [PMCID]

[28] Fond G, Godin O, Schurhoff F, Berna F, Bulzacka E, Andrianarisoa $\mathrm{M}$, et al. Hypovitaminosis $\mathrm{D}$ is associated with depression and anxiety in schizophrenia: Results from the 
national FACE-SZ cohort. Psychiatry Res. 2018; 270:104-10. [DOI:10.1016/j.psychres.2018.09.024] [PMID]

[29] Yao Y, Fu S, Zhang H, Li N, Zhu Q, Zhang F, et al. The prevalence of depressive symptoms in Chinese longevous persons and its correlation with vitamin D status. BMC Geriatr. 2018; 18(1):198. [DOI:10.1186/s12877-018-0886-0] [PMID] [PMCID]

[30] Han B, Zhu FX, Yu HF, Liu S, Zhou JL. Low serum levels of vitamin $\mathrm{D}$ are associated with anxiety in children and adolescents with dialysis. Sci Rep. 2018; 8(1):5956. [DOI:10.1038/ s41598-018-24451-7] [PMID] [PMCID]

[31] Ju SY, Lee YJ, Jeong SN. Serum 25-hydroxyvitamin D levels and the risk of depression: A systematic review and meta-analysis. J Nutr Health Aging. 2013; 17(5):447-55. [DOI:10.1007/s12603-012-0418-0] [PMID]

[32] Casseb GAS, Ambrosio G, Rodrigues ALS, Kaster MP Levels of 25-hydroxyvitamin D3, biochemical parameters and symptoms of depression and anxiety in healthy individuals. Metab Brain Dis. 2019; 34(2):527-35. [DOI:10.1007/s11011018-0371-7] [PMID]

[33] Ulusoy H, Sarica N, Arslan S, Ozyurt H, Cetin I, Birgul Ozer $\mathrm{E}$, et al. Serum vitamin $\mathrm{D}$ status and bone mineral density in fibromyalgia. Bratisl Lek Listy. 2010; 111(11):604-9. [PMID]

[34] Kwasky AN, Groh CJ. Vitamin D and depression: Is there a relationship in young women? J Am Psychiatr Nurses Assoc. 2012; 18(4):236-43. [DOI:10.1177/1078390312452451] [PMID]

[35] Macova L, Bicikova M, Ostatnikova D, Hill M, Starka L. Vitamin D, neurosteroids and autism. Physiol Res. 2017; 66(S3):S333-40. [DOI:10.33549/physiolres.933721] [PMID]

[36] Humble MB. Vitamin D, light and mental health. J Photochem Photobiol B. 2010; 101(2):142-9. [DOI:10.1016/j.jphotobiol.2010.08.003] [PMID]

[37] Pertile RA, Cui X, Eyles DW. Vitamin D signaling and the differentiation of developing dopamine systems. Neuroscience. 2016; 333:193-203. [DOI:10.1016/j.neuroscience.2016.07.020] [PMID]

[38] Stockmeier CA. Involvement of serotonin in depression: evidence from postmortem and imaging studies of serotonin receptors and the serotonin transporter. J Psychiatr Res. 2003; 37(5):357-73. [DOI:10.1016/S0022-3956(03)00050-5]

[39] Mansournia MA, Ostadmohammadi V, Doosti-Irani A Ghayour-Mobarhan M, Ferns G, Akbari H, et al. The effects of vitamin D supplementation on biomarkers of inflammation and oxidative stress in diabetic patients: A systematic review and meta-analysis of randomized controlled trials. Horm Metab Res. 2018; 50(6):429-40. [DOI:10.1055/a-0630-1303] [PMID]

[40] Akbari M, Ostadmohammadi V, Lankarani KB, Tabrizi R, Kolahdooz F, Heydari ST, et al. The effects of vitamin D supplementation on biomarkers of inflammation and oxidative stress among women with polycystic ovary syndrome: A systematic review and meta-analysis of randomized controlled trials. Horm Metab Res. 2018; 50(4):271-9. [DOI:10.1055/s-0044-101355] [PMID]

[41] Jamilian H, Amirani E, Milajerdi A, Kolahdooz F, Mirzaei $\mathrm{H}$, Zaroudi $\mathrm{M}$, et al. The effects of vitamin D supplementation on mental health, and biomarkers of inflammation and oxidative stress in patients with psychiatric disorders: A systematic review and meta-analysis of randomized controlled trials. Prog Neuropsychopharmacol Biol Psychiatry. 2019; 94:109651. [DOI:10.1016/j.pnpbp.2019.109651] [PMID]

[42] Alrefaie Z, Alhayani A. Vitamin D(3) improves decline in cognitive function and cholinergic transmission in prefrontal cortex of streptozotocin-induced diabetic rats. Behav Brain Res. 2015; 287:156-62. [DOI:10.1016/j.bbr.2015.03.050] [PMID]

[43] Larson MJ, Paasche-Orlow M, Cheng DM, Lloyd-Travaglini C, Saitz R, Samet JH. Persistent pain is associated with substance use after detoxification: A prospective cohort analysis. Addiction. 2007; 102(5):752-60. [DOI:10.1111/j.13600443.2007.01759.x] [PMID]

[44] Rosenblum A, Joseph H, Fong C, Kipnis S, Cleland C, Portenoy RK. Prevalence and characteristics of chronic pain among chemically dependent patients in methadone maintenance and residential treatment facilities. JAMA. 2003; 289(18):2370-8. [DOI:10.1001/jama.289.18.2370] [PMID]

[45] Karasz A, Zallman L, Berg K, Gourevitch M, Selwyn P, Arnsten JH. The experience of chronic severe pain in patients undergoing methadone maintenance treatment. J Pain Symptom Manage. 2004; 28(5):517-25. [DOI:10.1016/j.jpainsymman.2004.02.025] [PMID]

[46] Reginato AJ, Falasca GF, Pappu R, McKnight B, Agha A. Musculoskeletal manifestations of osteomalacia: Report of 26 cases and literature review. Semin Arthritis Rheum. 1999; 28(5):287-304. [DOI:10.1016/S0049-0172(99)80013-4]

[47] Plotnikoff GA, Quigley JM. Prevalence of severe hypovitaminosis D in patients with persistent, non-specific musculoskeletal pain. Mayo Clin Procs. 2003; 78(12):1463-70. [DOI:10.4065/78.12.1463] [PMID]

[48] Black PN, Scragg R. Relationship between serum 25-hydroxyvitamin $\mathrm{d}$ and pulmonary function in the third national health and nutrition examination survey. Chest. 2005; 128(6):3792-8. [DOI:10.1378/chest.128.6.3792] [PMID]

[49] Broe KE, Chen TC, Weinberg J, Bischoff-Ferrari HA, Holick MF, Kiel DP. A higher dose of vitamin d reduces the risk of falls in nursing home residents: A randomized, multipledose study. J Am Geriatr Soc. 2007; 55(2):234-9. [DOI:10.1111/ j.1532-5415.2007.01048.x] [PMID]

[50] Ford ES, Ajani UA, McGuire LC, Liu S. Concentrations of serum vitamin $\mathrm{D}$ and the metabolic syndrome among U.S adults. Diabetes Care. 2005; 28(5):1228-30. [DOI:10.2337/diacare.28.5.1228] [PMID]

[51] Wang TJ, Pencina MJ, Booth SL, Jacques PF, Ingelsson E, Lanier K, et al. Vitamin D deficiency and risk of cardiovascular disease. Circulation. 2008; 117(4):503-11. [DOI:10.1161/ CIRCULATIONAHA.107.706127] [PMID] [PMCID] 